\#054 Fibroma idiopático num paciente jovem - A propósito de um caso clínico

Joana Figueiredo Santos, Sarah Goolamhussen*, Jorge Martins, Tinoco Torres Lopes, Filipa Santos Bexiga

Instituto de Ciências da Saúde de Viseu da Universidade Católica Portuguesa

Introdução: O fibroma é o tumor benigno de tecidos moles mais encontrado na cavidade oral. Cli-nicamente apresenta-se como uma lesão em forma de cúpula com base séssil ou pediculada e super-fície lisa e firme, de coloração rosa e crescimento lento e limitado (não crescendo mais do que $2 \mathrm{~cm}$ ). A maioria dos casos apresentam-se assintomáticos à palpação, a menos que sejam provocadas ulcerações traumáticas na superfície. Localiza-se mais comumente em áreas favoráveis a trauma como a gengiva inferior, bordo lateral da língua, lábio, palato duro e mucosa jugal.

Descrição do caso clínico: Paciente do sexo masculino, 21 anos de idade, ASA I, sem antecedentes pessoais, familiares e dentários relevantes e com hábitos tabágicos. Na inspeção oral verificou-se a existência de um aumento nodular arredondado, duro e ligeiramente móvel, com mucosa superficial lisa, com coloração rosa e com alguma pigmentação na mucosa a revestir. Não apresentava ulceração nem sintomatologia dolorosa. O paciente referiu crescimento progressivo durante o período de 4 anos. A lesão tinha $10 \mathrm{~mm}$ de comprimento e $5 \mathrm{~mm}$ de diâmetro mesiodistal, encontrando-se asso-ciada ao dente 33 na região vestibular da gengival marginal e aderida e sem evidências radiográfi-cas. Nega histórico de trauma ou inflamação relacionados com a lesão apresentada, o que tornou a sua etiologia inconclusiva. De acordo com as características apresentadas foi realizado um diagnós-tico provisório de fibroma e para confirmação do mesmo foi realizada uma biópsia excisional atraumática na Clínica Dentária Universitária de Viseu para posterior exame anatomo-patológico.

Discussão e conclusões: O tratamento de eleição foi excisão cirúrgica dado o caráter idiopático da lesão, as suas reduzidas dimensões e aparência homogénea, bem como por antecedentes de descon-forto relatado pelo paciente. A realização de uma técnica atraumática teve como objetivo a máxima preservação possível de gengiva aderida, de forma a melhorar o prognóstico e evitar uma futura recessão gengival na região do dente 33. 0 diagnóstico obtido pela análise anatomo-patológica detetou a presença de um fibroma o que correspondeu ao diagnóstico provisório efetuado. São realizados controlos periódicos desde abril de 2018 para deteção de possíveis recidivas comuns nestas lesões. Verifica-se a inexistência de qualquer recessão gengival na zona de intervenção no período atual após a recuperação.

http://doi.org/10.24873/j.rpemd.2018.11.292

\section{\#055 Disfunção Temporo Mandibular como primeira manifestação de Artrite Reumatóide}

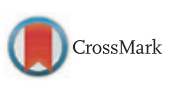

Ana Boyé de Sousa*, Olga Vascan, Sara Garrido, Conceição Sepúlveda, Manuela Carrilho, José Pedro Figueiredo

CHUC

Introdução: A artrite reumatóide é uma doença inflamatória crónica auto-imune, de etiologia desconhecida, que atinge principalmente as articulações. É uma patologia relativamente frequente, com prevalência de 0,5 a 1\% da população, e incidência de 3 casos por 10.000 pessoas, afetando mais mulheres do que homens, mais frequentemente entre os 35 e 50 anos, podendo surgir em qualquer idade. Ao nível articular há uma inflamação crónica da sinovial, com destruição articular que pode ser maciça levando a acentuada incapacidade.

Descrição do caso clínico: Os autores descrevem um caso de uma mulher de 58 anos, que recorreu ao Serviço de Urgência de Estomatologia por dor nas articulações temporo mandibulares com componente inflamatório marcado, de vários meses de evolução, com agravamento recente levando à limitação da abertura bucal. Medicada sintomaticamente e encaminhada à Consulta Externa para controlo, apresentando de novo poliartralgias marcadas e edema nas articulações distais, mãos, punhos e joelhos, simetricamente. Encaminhada à Consulta Externa de Reumatologia, onde foi diagnosticada com Artrite Reumatóide seronegativa e medicada com corticóide (prednisolona), metotrexato e salazoprina. Concomitantemente na nossa consulta foi realizada goteira de relaxamento muscular.

Discussão e conclusões: A artrite reumatóide é uma patologia comum, no entanto a apresentação inicial de artralgias isoladas da articulação temporo mandibular é menos frequente. Este caso realça a importância da preocupação sistémica que o estomatologista deve ter na avaliação de um doente, apesar das queixas dirigidas ao aparelho estomatognático. http://doi.org/10.24873/j.rpemd.2018.11.293

\#056 Carcinoma Verrucoso e biópsia incisional inconclusiva - a propósito de um caso clínico

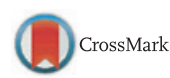

Gonçalo Cunha Coutinho*, José Ferreira, Cecília Franco Caldas, Rita Simão, Miguel Amaral Nunes, Francisco Salvado

Clínica Universitária de Estomatologia, Centro Hospitalar Lisboa Norte; FMUL

Introdução: O carcinoma verrucoso é uma variante rara e de baixo grau do carcinoma pavimento-celular. É mais frequente em homens, a partir dos 50 anos, e associa-se ao consumo de tabaco e álcool. Pode, porém, aparecer em mulheres e na ausência de fatores de risco. Apresenta-se geralmente como uma placa espessa, de distribuição difusa, bem demarcada e indolor, com projeções papilares ou verruciformes, mais frequentemente em áreas edentadas dos rebordos alveolares e nos vestíbulos orais e/ou mucosa jugal. Apesar de localmente agressivo, o seu crescimento é indolente e a metastização é pouco frequente. O diagnóstico é histológico, podendo, porém, confundir-se com outras entidades de apresentação semelhante, nomeadamente hiperplasia verrucosa, hiperplasia pseudoepitelial ou leucoplasia proliferativa verrucosa. Estas lesões verrucosas podem, também, incluir zonas de carcinoma verrucoso.

Descrição do caso clínico: Mulher de 82 anos, encaminhada pelo seu médico de família por lesão branca extensa do rebordo alveolar do $2 .^{\circ}$ quadrante, vestíbulo e mucosa jugal adjacentes, com aspecto nodoso de consistência dura e indo- 